\title{
New Territories: Reimagined Interiorities
}

\begin{abstract}
At a time where boundaries within society, culture, and technology are continually challenged and redefined, even the commonly understood binary oppositions within areas such as gender, age, and digitality (Negroponte, 1995) are becoming less visible, measurable, and socially accepted. In this new realm where even physical reality is encroached upon by the digital, are the tangible and perceived distinctions between interior and architecture also becoming extinct? The emergence of more flexible and transitional space appears to not only blur the boundaries of inside and outside, interior and architecture, but also the previous distinctions of function. Space is no longer solely intimated by visual cues, materiality, or the physicality of walls and interior objects. Instead, we see increased 'function neutrality' within buildings, with rising opportunity for user interpretation and take-over. This renewed focus on the user can enrich our built environment as we embrace new equality of the interior and relish its new freedom and voice.
\end{abstract}

Keywords: interiority, architecture, thresholds, reimagined, temporality

Correspondence Address: Lucy Marlor, Northumbria University Design School, CCE2, Northumbria University, Newcastle Upon Tyne. NE1 8ST Email: lucy.marlor@ northumbria.ac.uk 


\section{Introduction}

The common conceptualisation of the interior and its role within architecture and design are being reconsidered. The interior is commonly envisaged as a static entity, anchored to, and perhaps, limited by its architectural keeper. Traditionally the interior can be viewed as a tactile and decorative interface between architecture and the user. It is by the interior, which we (the user) engage and experience architecture. The duality of the interior and architecture has often resulted in them being observed as a binary pair, opposing and distinct, but reliant on each other to exist (Soderqvist, 2011). However, over the last century, there has been a shift emerging where the boundaries between the two appear to be blurring. To identify change and look to this evolving interior of the future, we must first explore the positioning of the interior within society, culture, and design. Penny Sparke (2010) frames the changing position of the modern interior within a range of disciplines and situations during this period. Three significant forces appear to have had a notable impact on the development and perception of the interior in society; architectural modernism (space), the cultural, social and psychological based connection between interiors and those who occupy them (place), and the historical interior of the decorative arts (taste). To understand the modern interior, these subjective ways of viewing the interior must be recognised, and we should explore the "roles of 'interiority' and 'representation,' both visually and literary" (Sparke, 2010, p. 7).

A conflict appears to have developed between the spatially oriented interior associated with the modernist architects, designers, and planners of the 20th century and the interior 'places' relating to the human inhabitant, which created and reinforced their cultural identities. This line of thought begins to delineate the conceived space of the designer and architect and the user-focused reality of the space as lived and experienced, also discussed by Psarra (2009) and Lefebvre (1995). The latter can be described as "discussion into the areas of fashion, taste, identity, and lifestyle - the defining features of modernity as experience by many inhabitants of the Western, industrialized world" (Sparke, 2010, p. 8). A significant shift is noted, from a focus on the (designed) conceptual nature of the interior to a concentration on the user of the space, a projection of self and recognition of individual perception on a range of levels, including emotional and psychological. The preconception of the modern interior as a spin-off of the minimal and pure forms of modernism is incorrect. Instead, Sparke (2010) suggests that the defining quality of the modern condition is related to

its social, cultural, and psychological relationship with its users, inhabitants; its continuity with history; its links with the 
fashion system; and roles of both amateur homemakers and professional decorators interested in the interior as a site for (mostly feminine) self-expression and identity formation. (p. 14)

The acknowledgement of a relationship between the user and space and an interpreted spatial experience appears to be a significant evolution within the modern interior, specifically its growing allegiance and responsiveness to the changes in society defining its modernity. Walter Benjamin (2004) refocuses the domestic interior as the most important emergence within mid 19th century industrial modernity-along with the separation of public and private space, in particular dwelling and place of work.

The demarcation of the three positions and perspectives of the interior as 'space, 'place,' and 'taste' also help outline the type of traditional interior, which perhaps remains as a residual perception in many people's minds. Taste, and the traditional and historic framework it situates the interior in, also relates to the turn towards private (domestic) from the public (workspace). Benjamin (2004) references individuals and their influence and connection to personal space and further outlines this new focus on the user relating to "place" (p. 190). This emphasis on the domestic and acknowledgement of the reflection of the inhabitant in everyday space is discussed by multiple authors. Todd and Mortimer (1929) define it as being the spatial projection of the self, while it is depicted as the manifestation of the occupant and their spatial practice within the materiality and object content of the interior by Atmodiwirjo \& Yatmo (2018). Pimlott (2018) describes the personal projection of the user within the (domestic) interior, specifically relating it to the concept of interiority and suggests that "interiority pertains to the inner life of the individual" (p. 2). The modern interior is ever-evolving as it follows economic, social, technological, cultural, and psychological drivers and is, as Walter Benjamin (2010) suggested, "a mirror of modern life itself" (p. 16). McCarthy (2005) further advances this description of the interior to that of interiority, describing it as "a transformative concept, dependent on social, cultural, physical and technological developments in our own specific societies" (p. 122).

It appears that the evolution of space, and specifically the interior, to a user-centric device is long overdue, and this renewed relationship between inhabitant and environment is driving the change. Lefebvre (1991) described the potential disconnect between conceived and lived (architectural) space as being due to modern space tending to be wrongly framed by the egocentric vision of the architect or designer, rather than focused on its user-based and experiential 
purpose. The mistake is forgetting that "space does not consist in the projection of an intellectual representation, does not arise from the visible-readable, but that it is first of all heard (listened to) and enacted (through physical gestures and movements)," placing importance on the understanding of the lived and experienced space (Lefebvre, 1991, p. 200).

Changes in how architecture is viewed and experienced within our generation also follow suit in the mirroring of modernity. The temporality of the digital age and what Negroponte (1995) describes as 'digitality' produces the fleeting nature of experiences. A focus on the printed image and digital presentation as a medium to experience architecture has resulted in a distancing from the human body and the level of tactility associated. This detachment from reality turns architecture into to a visual stage set and lacks true authenticity as a representation of these notable cultural changes (Pallasmaa, 2011). These aspects compounded create a more physically and digitally mobile user within the built environment and society. As a result, a more dynamic and transient spatial experience is materialising, extending the territorial reach of the interior.

We can observe an insurgence of impromptu 'placemaking' and the momentary portrayal of the interior as an 'event' (Adams and Marlor, 2019a). There appear to be new ways of viewing and designing the interior, which is not entirely physical or object-based and instead is focused on the evolving characteristics of the user. This territorial expansion is demonstrated by interior experiences occurring outside of the traditionally understood conditions of the interior. Through a selection of case study examples, this paper will explore four realworld scenarios where this spatial evolution is evidenced: open platform interiors-occurring within architecture but where the neutrality of the design actively empowers the user to define the function and drive inhabitation; momentary spatial encounterssuch as 'pop-up' interiors; interiority in non-interior spaces; and virtual interiority - which transcends the physical world into the digital.

\section{Open Platform-User-Driven (Facilitated)}

The user has previously been guided by the division of space and the definition of purpose the interior commands. However, spaces are becoming less defined by boundaries, thresholds, and the permanent division of space. Voordouw (2018) suggests that since the age of modernism, the interior has slowly been weakened by its growing link to the exterior. Room function is not solely dictated by the position of walls and the interior envelope; instead, space more often becomes an open stage on which the interior event is played out, connected to 
the spatial needs of the user at that point in time. There will always be a need to divide specific rooms and spatial functionality in sectors such as healthcare, but civic, leisure, education, and workplace sectors are seeing an increasingly user-driven approach to the creation of public and communal spaces.

The refocussing of the user as the driver of spatial function in these sectors is visible in the design of more open and neutral spaces, which appear in a constant flux between functions. This creates an open platform for inhabitation and refocuses the user as the driver of spatial function. Lefebvre (1991) suggested that actually space is not defined by the physical delineations of architecture; instead, "visible boundaries, such as walls or enclosures in general give rise for their part to an appearance of separation between spaces when in fact what exists is ambiguous continuity" (p. 87). This ambiguity acts as an enabler for the expansion and movement of interior functions between spaces dictated by the human user.

This open call for user definition can be seen at the LocHal Library in Tilburg, Netherlands. The space is an innovative hybrid form of library, where users can source books and media, but also be part of wider knowledge exchange and production. The library occupies the former LocHal locomotive shed, which has been reinterpreted to house an open style library, co-working spaces, exhibition, lecture and events spaces, and a children's section. The cavernous industrial site has been celebrated through its reincarnation, with the new interior maintaining vast open sightlines dissected only by the colossal structural members which create its frame. The layering of open levels, connected by a tiered landscape of hybrid staircase and seating areas, creates vast auditoriums for users to inhabit or simply meander through as circulation space. The design has produced an open arena for a user-defined occupation where people can be viewed working alone, enjoying lunch in small groups, conducting breakout meetings, and even practising performance art. The purpose of the space is open to interpretation, and users claim it as they see fit. There are few interior tactics employed apart from the tiered landscape. However, levels of spatial intimacy are still experienced with the suggestion of territory defined by the linear and vertical boundaries of the steps. These aspects support the suggestion that interiority is not solely reliant on architectural enclosure (Morris, 2019).

The LocHal library also hosts more formalised devices for need-based adaption of space. In collaboration with Inside Outside's Petra Blaisse, expansive textile screens were designed to change the spatial structure of the auditoriums. These fabric walls hang dormant, waiting 
to be moved via computerised systems to divide spaces into smaller lecture theatres or open up space and become the backdrop to large scale events. Depending on the user's needs, the space reconfigures and transforms throughout the day, expanding and contracting. This textile acts as a malleable, flexible, dynamic interior envelope shadowing the user's needs, capable of reprogramming space within the fixed architectural container. In addition to the physical breaking of sightlines and feel of boundary and enclosure, these textile walls create an acoustic condition of intimacy and atmospheric delineation (Civic Architects, 2019).

Figure 1

Changing the spatial fabric. Petra Blaisse's

Re-Set, exhibited at La Biennale di Venezia 2021 (Photograph by Jean-Pierre Dalbérra)

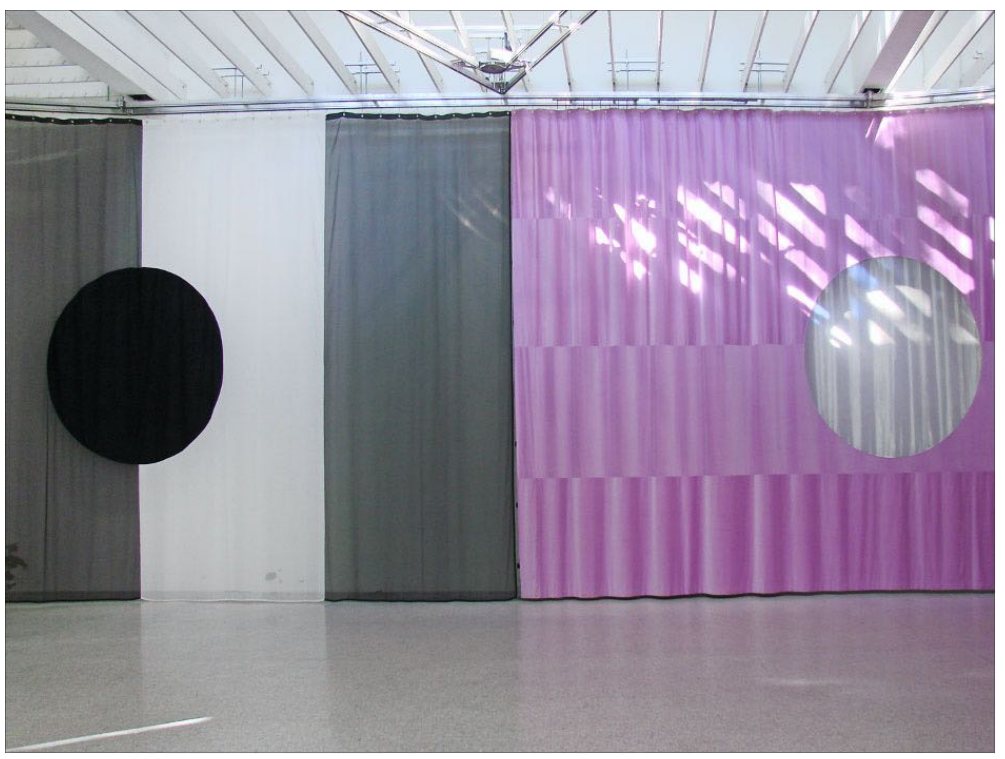

The reduced reliance on physical form and interior tactics to create the interior is discussed by Liz Teston (2020), who describes a type of interior experience found in the public arena that is unconnected to the architectural envelope. Teston (2020) defines a taxonomy of interiorities based on conditions; instead, 'public interiority' is described as a feeling of interior created by psychological, atmospheric, programmed, and form-based conditions. Psychological interiority is person centred experience (based on the interactions between a person and the built environment or between two people, shaped by context); form-based interiority is derived from physical architectural form which humans perceive; atmospheric interiority created by suggestions of atmosphere such as luminous, thermal, acoustic, tensions, energies between forms; programmed interiority is where programming (function) takes interior activities away from the interior and creates a new sense of interiority. 
In particular, Teston (2020) demonstrates a new realm of entirely nonform-based experiences of interiority. The physicality of our interior experience appears to be lessening and a more transcendental encounter is evolving. In the case of the LocHal library, we can observe Teston's psychological, form-based, and atmospheric conditions creating public interiorities.

There seems to be a developing understanding that the user has an increased input in the creation of an interior experience. They do not simply encounter a piece of architecture; instead, there is a performative engagement with it and production of experience via personal perception, whether this is impromptu as seen in the tiered interior landscape of LocHal library or more formally engineered as per the moveable screens. Dorita Hannah (2018) suggests that architecture is dependent on the creativity of the user, who actively help engineer their environment via perception and sensory engagement. In summary, although these open platform interiors are user driven, they are designer-enabled. The case study design demonstrates a discrete acknowledgement of the empowered status and increased mobility of the current and future users.

\section{Temporal Interiors (Momentary)}

Traditionally the interior can be viewed as the interchangeable lining of a building, and as such, generally has a shorter life cycle than its more permanent architectural anchor. However, an emerging wave of temporality in interiors has begun to reimagine the concept of the interior experience. So frequently, pop-up interiors are designed, installed, experienced and removed within a matter of weeks, days or even hours. Perhaps overlooked, the original momentary interior can be said to be the market stall, and this concept has not changed much in the development of pop-up interiors. The concept of the market stall challenges the preconceived boundaries of inside versus outside, interior versus architecture, and demonstrates the temporal qualities of the pop-up store (Adams \& Marlor, 2019b).

Momentary interiors have changed the goalposts in how we can view the interior. It is no longer reliant on architecture upon which to hang itself but instead can stand alone. Their finite nature means that these new types of interior appear dynamic, mobile and live, and as a result, have a performative quality. There is a subtle reorientation from the perception of interior from object to action. Pop-up interiors may occur as temporary events within larger designed spaces such as shopping centres and department stores, but perhaps more frequently within disused, vacant spaces. Interestingly, the bureaucracy in planning and development and the crippling prices of the high street has created 
stagnation in many available spaces within the built environment. The utilisation of these spaces by companies such as Meanwhile Space, Makeshift and Appear Here has created a new market of very short term leases. There is scope to suggest that this has actively encouraged this type of momentary business and temporality in the retail, leisure, and community interiors which occupy the spaces.

Figure 2

Successful use of 'meanwhile space' at Pop Brixton, London

(Photograph by Fred Romero)

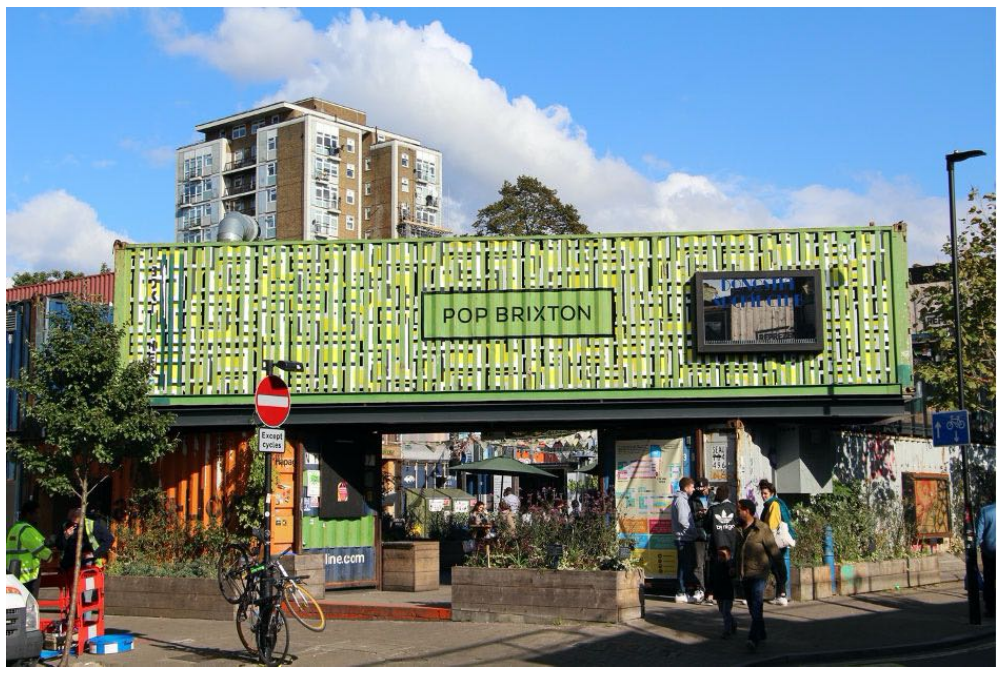

Some of these interiors are truly momentary, mirroring how a market stall pops up and is disassembled hours later. Some have longer life spans, generally due to popularity, but the materiality and constructions of a temporary structure and ability to be removed quickly in deconstruction terms such as Box Park in Shoreditch, Pop in Brixton (Figure 2), Common Ground in Seoul and Stack in Newcastle upon Tyne.

Boano Prišmontas's winning design for the Arch Challenge Project in collaboration with the Meanwhile Space organisation, has further challenged the notion of the momentary interior. The design consists of a system of dry jointed plywood parts, which is self-assembled, dismantled and redeployed in other locations. The interior structure is continually reconfigured to fit the next host site and was designed as a device to reactivate abandoned pocket spaces such as vacant railway arches, multi-storey car parks and church crofts (Prišmontas, 2018). As a result, it is not only the existing architecture that is re-purposed; it is the mobile interior that is also reimagined. The transformative ability, combined with the transient and fugacious quality of the interior, enters it into the new conceptual territory. 
The transitory nature of these interiors, again, replaces the previously immobile interpretation of the interior and refocuses its anchorage from the static architecture to the mobile user. Adams and Marlor (2019a) discuss these impermanent scenarios in which the interior can be viewed as more of an event or dynamic production. Dorita Hannah (2018) discusses the interior as a "kind of scenography that structures experience and interaction through open ended spatial dramaturgies orchestrating material and immaterial elements as temporal, interconnected, and mutable phenomena" (p. 300). Instead of questioning what a piece of architecture is, as an object, we should instead ask what the "fabricated environment (as a dynamic multiplicity) does", as an instigator of engagement and experience (Hannah, 2018, p. 301). We can see this sentiment demonstrated in The Shed, New York, an arts, performance and events space by Diller Scofidio + Renfro, which is framed on the original flexible architecture of Cedric Price's iconic Fun Palace (Figure 3). "Like its precursor, The Shed's open infrastructure can be permanently flexible for an unknowable future and responsive to variability in scale, media, technology, and the evolving needs of artists" (Diller Scofidio + Renfro, 2018, para. 4).

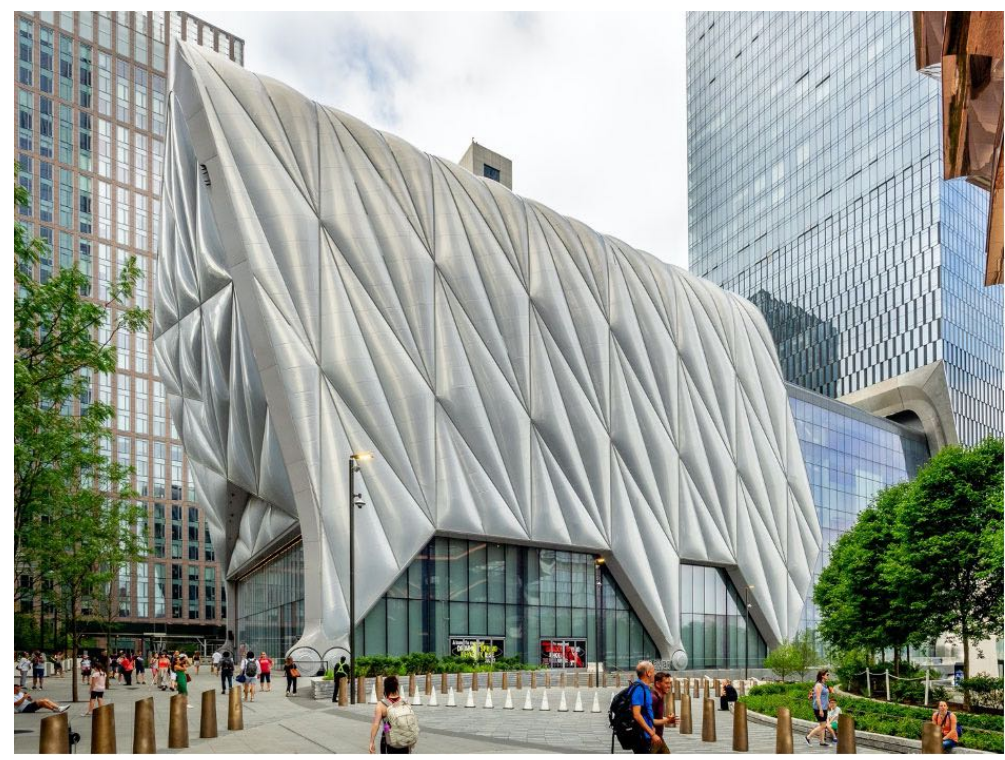

Figure 3

Moveable telescoping roof of The Shed, New York (Photograph by Ajay Suresh)

\section{Non-Interior Spaces (Exploratory)}

It also seems apparent that the user can have interior experiences in spaces that may not be entirely 'interior.' Where interior activities are performed in a non-interior setting, the user can still experience a sense of interiority. Teston (2020) rejects the need for interiority to 
anchor to a particular space or even be inside. Instead, it is related to the perceived character of a place, "Interiority is a condition of feeling inward, whether that condition is literally inside or a sensation of psychological otherness distinct from your physical surroundings or others around you" (Teston, 2020, p. 66). Le Corbusier (1929) famously created a sense of interiority in his Maison de Beistegui rooftop garden design in Paris simply by using visual cues referencing interior activities.

Figure 4

An interior moment within the exterior landscape, Belsay, Northumberland (Photograph by author)

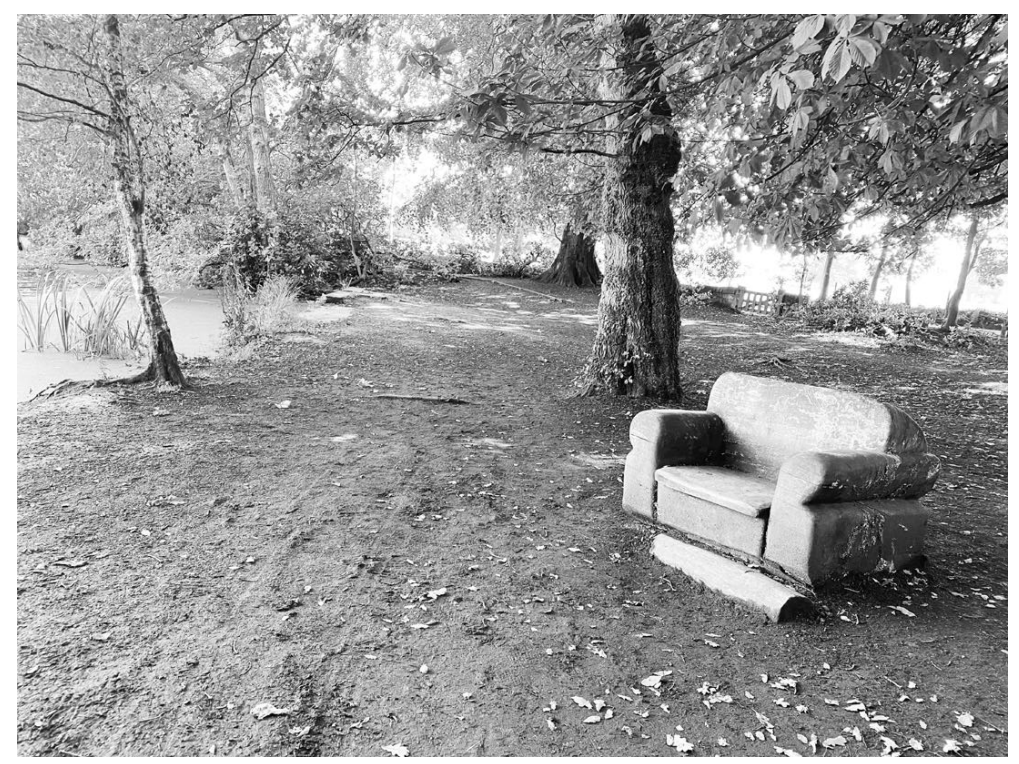

William H. Whyte (2001) and his Street Life Project explored why some urban spaces such as plazas and parks engaged the public, and some did not. Whyte (2001) identified conditions within these external landscapes, which helped create user experiences of interiority. The Plaza at Ludwig Mies Van der Rohe's Seagram Building, New York, was included in the study and famously attracted city-goers to stop and occupy its expansive exterior footprint. Interior activities are played out in the external environment with little reference to the conditions of the traditional interior (Figure 5). The building was the first of its kind, only using $40 \%$ of the site to house the building's footprint (Emporis, n.d.). As a result, the plaza sits within a significant void space within the built-up cityscape. There are areas of architectural enclosure, for example, where the ground floor is set back from the street, and the first-floor level creates a roof structure over it. However, the majority of the space is fully open. This leads us to observe other non-formbased conditions that create public interiority, in accordance with Teston's (2020) taxonomies of public interiority. 


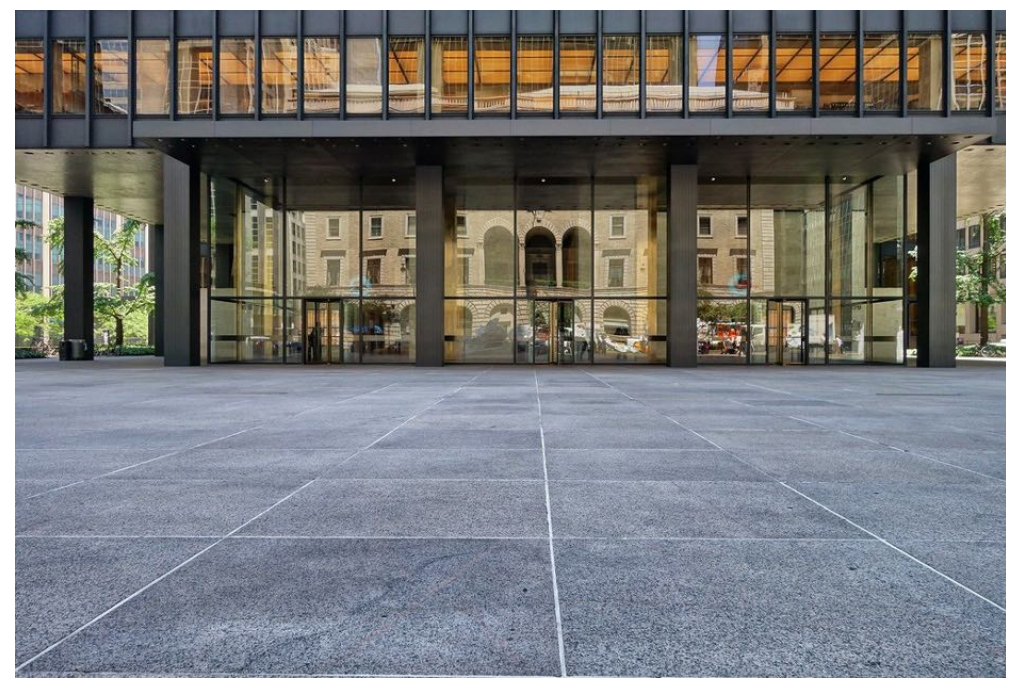

The success of the Seagram Plaza is partially due to the presence of a range of seating types on the steps, lips, and edges of the plaza. This encourages the user to pause, experience the site (and other people) and carry out interior activities such as meetings, eating lunch, and work tasks. In addition, several atmospheric conditions within the plaza create the feeling of entering and being inside a spatial zone. Changes in materiality suggest an entry threshold as the user passes from the coarse finish of the sidewalk onto the oversized pink granite paving of the plaza. The framed openness of the void space, against the solid verticality of the surrounding buildings, creates an atmospheric volume. Luminous interiority (Teston, 2020) can be observed via the shadows cast from the imposing buildings, which again delineate the boundary.

\section{Virtual Interiority (Transcendent)}

Google Maps, which launched in 2005, and later Google Street View in 2007, has significantly changed how we explore space within the built environment virtually (Reid, 2020). We can now experience, in a humanised view, new locations from the comfort of our own (home) device. This type of spatial experience opens up a virtual realm of perception and presentation of space, tying in with the framing of life, culture, persona and general 'content.' An extension of this virtual world opened up in 2011 when Google launched Indoor Maps, which allows exploration of public interiors in the same way the exterior has previously been documented. Within the interiors now available to be explored online are spaces such as museums, transportation hubs such as train stations and airports, shopping centres, retail, and leisure (Google, n.d.). This, combined with the ability to present humanised
Figure 5

Seagram Building

Plaza, New York (Photograph by Iker Alonso) 
street view with interior mapping (plans), has created a new type of interior experience and renewed interest in the hidden interiors that lie behind the facades of the Street View cityscape.

Francesca Murialdo (2019) explores the effect of the emergence of Airbnb on the perception of the interior, positing that it is a "two-way mechanism (instrument) able to change the cultural and material role of interiors" (p. 179), instigated by the ability to view inside interior spaces from a distance and reflect on new types of interiority and our perceptions of them. This new way of viewing the interior in the digital realm, allows us to connect to virtual interiorities in a way that has not been seen before. We can connect to the suggestion of home, culture and intimate space via the presented visualisation of the designer or owner. As Murialdo (2019) suggests, this is a twoway process, and we do not simply view the interior as an object; we engage with it in a new type of interiority. In John Berger's (1972) book Ways of Seeing, he outlines this multiway mechanism of viewing. While describing the complexity of connections and layers of information made while visualising, Berger (1972) states that "We never look at just one thing, we are always looking at the relationships between things and ourselves" (p. 8).

In the unprecedented conditions experienced in the 2020 COVID-19 outbreak, an interesting presentation of person-centred interiority became visible. The experience of shared space, whether in work meetings or social parties, became entirely virtual. A person's intimate spatial zone was represented within the rectangular capture of the laptop, phone, or tablet. The digital architecture of the room creates a space for conversing. In these new virtual meeting spaces, the user presented their own interior identity whilst being presented with that of the other users, and in doing so, creating a third space where both (or more) parties meet and engage. Suggestions of home, family, style, affluence, and culture are framed within a single visual. Perhaps inadvertently to begin with but later designedly, camera orientation, choice of location, and well-placed personal artefacts quickly became a projection of identity or desired identity. In this sense, the interior became much more than a contextual environment or background. Instead, it played a significant role in how people were perceived. The interior became a communicative tactic to broadcast a personal message, and visually it became an extension of the user.

This live, shared experience of other interior space differentiates this new interiority from that of the static staged photo of Airbnb or Google indoor mapping. The lived experience and emersion of 
a video call, plus the engagement and exchange with other users within the virtual enclosure, creates its unique type of intimacy. Strangely the user does not see their own interior space, but shares in the virtual background and architecture of their partner or group, creating a shared interiority. There is no doubt that although virtual, there is an immersive interior experience and a sense of shared space.

The potential for development in this area is extensive and is being explored by practices such as Space Popular in ways that completely re-imagine the notion of meeting space. Founders Lara Lesmes and Fredrik Hellberg present the possibilities for sharing video calls where the users' home environments overlap, echoing a Venn diagram (Space Popular, 2019).

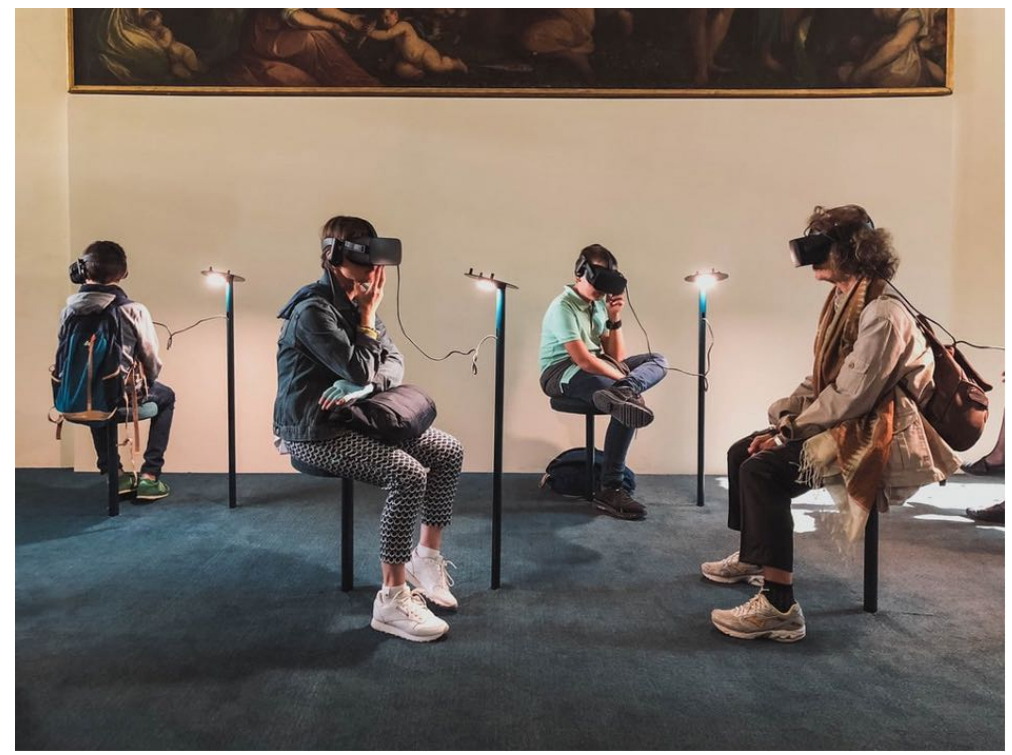

Figure 6

Virtual spatial experience (Photograph by Lucrezia Carnelos)

This creates a hybrid space in which furniture can be rearranged to allow the users to sit next to each other, demonstrating a totally new type of augmented reality and virtual connectedness. Adrian Forty (2013) describes space in three ways, "as enclosure, as continuum (connection between interior and exterior space) and as an extension [emphasis added] of the human body (formed by human activity)" (p. 266). The last description of space resonates with virtual interiority, namely an interiority created as an extension of the user and formed by engagement with others. It would appear that virtual interiority spans all of these qualities and is an area where there is vast scope for future development and exploration. 


\section{Conclusion}

This paper draws upon four different ways in which the interior is expanding into new territories. We have identified the traditional qualities of the interior, introduced the interior theory, and evidenced this theory using case study examples. It is possible to have interior experiences in unexpected locations, scenarios, and via alternative mediums-whether led by designers as in the open platform (facilitated) and momentary (temporal) interior case studies, or impromptu and user-driven as seen in the non-interior (exploratory) and virtual (transcendent) space examples. The case studies point to a more dynamic, organic, evolving interior in continual change as it mirrors modernity. At the centre of this idea seems to be the user, with the established template for the interior experience being deconstructed and redirected to envelop and move with the individual. The notion of what the interior is and the definition of interiority is being reformed to meet our contemporary societal needs, driven by design, a new understanding of contemporary inhabitation and most importantly, the user.

\section{References}

Adams, R., \& Marlor, L. (2019a). A spatial diorama: the act of the interior (A five act play). In G. Brooker, H. Harris, \& K. Walker (Eds.), Interior futures (pp. 28-39). Crucible Publications.

Adams, R., \& Marlor, L. (2019b). Breaking the binary oppositions of the interior: A momentary permanence. Interiority, 2(2), 113-128. https://doi.org/10.7454/in.v2i2.58

Alonson, I. (2014). Seagram Building New York [Photograph]. Flickr. https://www.flickr.com/photos/finchermac/15174153854

Attiwill, S. (2018). Urban interiority as collective individuation. In P. Atmodiwirjo, \& Y. A. Yatmo (Eds.), [in]arch international conference 2018-The stories of interior: Multiple perspectives on interiority (pp. 53-62). Department of Architecture Faculty of Engineering Universitas Indonesia.

Atmodiwirjo, P., \& Yatmo, Y. A. (2018). Interiority in everyday space: A dialogue between materiality and occupation. Interiority, 2(10), 1-4. https://doi.org/10.7454/in.v2i1.56

Benjamin, W. (2004). The Arcades Project (H. Eiland \& K. McLaughlin, Trans.). Harvard University Press.

Berger, J. (1972). Ways of seeing. Penguin Books.

Carnelos, L. (2018). Unknown [Photograph]. Unsplash. https://unsplash. com/photos/IMUwe-p1yqs 
Civic Architects. (2019). LocHal Public Library Tilburg. https://www. civicarchitects.eu/projects/lochal-tilburg

Dalbera, J-P. (2012). Re-set, La Biennale di Venezia 2021 [Photograph]. Flickr. https://www.flickr.com/photos/dalbera/8132711535

Diller Scofidio + Renfro. (n.d.). The Shed, New York, NY. https://dsrny. com/project/the-shed

Emporis. (n.d.). Seagram Building. https://www.emporis.com/buildings/ 115572/seagram-building-new-york-city-ny-usa

Forty, A. (2013). Words and buildings: A vocabulary of modern architecture. Thames and Hudson.

Google. (n.d.). Go inside with indoor maps. Google. https://www. google.com/maps/about/partners/indoormaps/

Hannah, D. (2018). Event-space: A performance model for spatial design. In G. Marinic (Ed.), The interior architecture theory reader, (pp. 300-309). Routledge. https://doi. org/10.4324/9781315693002

Lefebvre, H. (1991). The production of space. Wiley-Blackwell.

McCarthy, C. (2005). Towards a definition of interiority. Space and Culture, 8(2), 112-125. https://doi.org/10.1177/ 1206331205275020

Morris, A. (2019, February 27). Civic architects creates public library in vast locomotive shed. Dezeen. https://www.dezeen. com/2019/02/27/lochal-public-library-civic-architects/

Murialdo, F. (2019). The new digital interiorscape and the edited Airbnb interior. In G. Brooker, H. Harris, \& K. Walker (Eds.), Interior futures (pp. 178-190). Crucible Publications.

Negroponte, N. (1995). Being digital. Hodder and Stoughton.

Pallasmaa, J. (2011). An architecture of the seven senses. In L. Weinthal (Ed.), Toward a new interior: An anthology of interior design theory (pp. 40-49). Princeton Architectural Press.

Pimlott, M. (2018). Interiority and the conditions of the interior. Interiority, 1(1), 5-20. https://doi.org/10.7454/in.v1i1.5

Prišmontas, B. (2018). The Arches Project. https://www. boanoprismontas.com/thearchesproject

Psarra, S. (2009). Architecture and narrative: The formation of space and cultural meaning. Routledge. 
Reid, E. (2020, February 6). A look back at 15 years of mapping the world. Google. https://www.blog.google/products/maps/ look-back-15-years-mapping-world/

Romero, F. (2016). London-Pop Brixton [Photograph]. Flickr. https:// flickr.com/photos/129231073@N06/31270115413

Soderqvist, L. (2011). Structuralism in architecture: A definition. Journal of Aesthetics \& Culture, 3(1), 1-6. https://doi. org/10.3402/jac.v3i0.5414

Space Popular. (2019). The Venn Room [Exhibition]. Estonian Museum of Architecture, Estonia. http://www.spacepopular.com/ exhibitions/2019---the-venn-room

Sparke, P. (2010). The modern interior: A space, a place or a matter of taste?. Interiors Design/Architecture/Culture, 1(1), 7-17. https://doi.org/10.2752/204191210791602276

Sparke, P. (2008). The modern interior revisited. Journal of Interior Design, 34(1), v-xii. https://doi.org/10.1111/j.1939-1668.2008.00002.x

Suresh, A. (2019). The Shed-Complete [Photograph]. Flickr. https:// www.flickr.com/photos/ajay_suresh/48206488176/

Teston, L. (2020). On the nature of public interiority. Interiority, 3(5), 61-82. https://doi.org/10.7454/in.v3i1.72

Todd, D., \& Mortimer, R. (1929). The new interior decoration: An introduction to its principles, and international survey of its methods. B. T. Batsford.

Voordoow, J. (2018). Topology and interiority: Folding space inside. In G. Marinic (Ed.), The interior architecture theory reader (pp. 318-326). Routledge.

Whyte, W. H. (2001). The social life of small urban spaces (8th ed.). Ingram.

Zumthor, P. (2006). Atmospheres: Architectural environments, surrounding objects. Birkhauser. 